\title{
Different Perspectives on Teacher Burnout
}

\author{
Msc. Ornela Zhilla \\ University of Tirana, Faculty of Social Sciences, Department of Psychology and Pedagogy
}

\section{Doi:10.5901/mjss.2014.v5n27p1254}

\begin{abstract}
The aim of this study was to describe different theoretical perspectives on teacher burnout and to excplain why teacher burnout. For these purpose a review of different articles and books on teacher burnout is completed. The tasks of teachers are demanding and heavy. It appears that annually many teachers feel unable to carry on with their jobs. Results from a considerable number of studies into this subject showed that teaching has high costs for teachers.
\end{abstract}

Keywords: burnout, stress, personal stressors

\section{Introduction}

Teacher burnout has been described as a syndrome resulting from prolonged teacher stress, characterised by emotional, physical and attitudinal exhaustion. Work conditions like poor career structure and low wages, are among the main factors that contribute to teacher job dissatisfaction and the intention to leave the teaching profession. Teachers who no longer have positive feelings about their students and feel drained are experiencing the second component of teacher burnout, depersonalisation. Finally, the third aspect of teacher burnout is a feeling of low personal accomplishment from their job, an aspect particularly crucial for teachers . (Panagopoulos,Anastasiou\&Goloni ,2014)

This paper describes different perspectives on teacher burnout. Teaching is a highly stressful occupation . Johnson,Cooper,Cartwright,Donald,Taylor,Millet (2005), described stressful occupations and made some comparisons between 26 different occupations. For each occupation was measured physical health, psychological well-being and job satisfaction. After listing these occupations in rank order , teaching results the second most stressful occupation.

In a study conducted by Evers,Browers,\&Tomic,(2002) teacher burnout is presented as a national concern problem for many countries. In the United States $5 \%$ to $20 \%$ of teachers experience burnout at some point during their teaching career.During the year 1990 in Great Britain 1/3 of all teachers view teaching as an exctremely stressful occupation. In Denmark teachers are not capable to cope with their job stressors in contrast with all the population who works. Also in Netherland during the year $1994,44 \%$ of all teachers declared themselves as not capable to work. Innability to work because of psychological stressors at work is known as the burnout syndrome.

According to Panagopoulos,Anastasiou \& Goloni , (2014) ;Alarcon ,Bowling \&Eschelman ,(2009) Teacher burnout is a syndrome resulting from prolonged teacher stress, characterised by emotional, physical and attitudinal exhaustion .Work conditions like poor career structure and low wages, are among the main factors that contribute to teacher job dissatisfaction and the intention to leave the teaching profession. Teachers who no longer have positive feelings about their students and feel drained are experiencing the second component of teacher burnout, i.e. depersonalisation. Finally, the third aspect of educators' burnout is a feeling of low personal accomplishment from their job, an aspect particularly crucial for teachers .

\section{Different Perspectives on the Concept of Burnout}

According to Byrne (1999) the concept of burnout has been shaped by four perspectives.Freudenberger's approach to burnout is the clinical perspective. Burnout represents a state of exhaustion that results from working too intensely and without concern for one's needs. The syndrome characterized individuals whom he perceived as paying a high price to help others.

The social -psychological prespective of Maslach and Jackson attempts to identify work environmental conditions conductive to burnout. These theorists emphasized how role-related stress could lead a person to excperience mental fatigue, the mechanic treatment of clients, and perceptions of a diminished ability to succed at his or her job.

Maslach and Jackson labeled these three aspects of burnout emotional exchaustion, depersonalization, and 
reduced personal accomplishment , respectively. Maslach viewed burnout as leading to worker withdrawal accompanied by a tendency to treat clients in a detached, dehumanized manner.

Cherniss also sought links between burnout and particular features of the work environment, and offered an organizational perspective. Cherniss argued that emotional exchaustion, depersonalization, and reduced personal accomplishment represent three coping mechanisms used in reaction to stressful, frustrating, or monotonous work.

The social -historical perspective on burnout, emphasizes the impact of society at large on the precipitation of burnout rather than the effect of the individual or the organization.

Terry (1997) described characteristics of teacher burnout. Burnout is characterized by exhaustion of physical or emotional strength resulting in physical,emotional and behavioral changes .Burnout occurs in five different areas: physical, intellectual, social, psycho-emotional and spiritual .Symptoms demonstrating this are of a physical nature and might include insomnia, absenteeism, tardiness and chronic colds. Tension headaches, neck strain, bruxism (grinding ones teeth together), sweating and accident proneness can also develop. Total fatigue in which one feels they can't spring back is common in burnout.

Intellectually teachers that experience burnout tend to experience role conflict and ambiguity and may be unclear regarding rights, duties and job responsibilities. A teacher may also question why they entered teaching. Teachers suffering from social burnout tend to display a growing cynicism, exhibited by increased insensitivity to children, parents, and the institution. Teachers tend to worry too much about students when suffering from burnout.Psycho-emotional burnout may be illustrated by the teacher withdrawing emotionally, moodiness, paranoia, depression,sadness, poor concentration and an apathetic demeanor. This specific stage of burnout can result in increased tobacco,alcohol or drug use. Other teachers may find themselves overeating and even going on shopping sprees. Spiritual burnout is a final stage that can occur if intervention is not sought. Usually the physical symptoms occur first but can even go unnoticed.

According to Bitsadze \& Japaredze (2011),burnout researchers can be distinguished by their approach to the solution of the problem. Psychological direction researchers suggest to help the burnout victims by obtaining and strengthening stress coping strategies, whereas sociological direction researchers suggest to look for the burnout causes within organizational systems and introduce changes in school management style and administration practices. Both approaches seem to give valuable insights in the study of burnout syndrome.

\section{Why Teacher Burn-Out?}

Dorman (2003) states that a common characteristic of occupations who work with other people including teaching is that the nature of the work can be highly emotional. For teachers, the potential for emotional stress is high since they work with classes of up to 35 students for long periods of time. The intensely relational nature of classrooms means that teachers are vulnerable to emotionally draining and discouraging experiences .Such experiences can lead to dysfunctional teacher behaviour with obvious implications for the teacher's well-being and student learning.

Burke,Greenglass,\&Schwarzer(1996)examined antecendents and consequences of psychological burnout among 362 teachers. The data in the study confirmed that teachers had high burnout levels because they are asked to assume multiple and often contradictory roles, including academic instruction, maintaining classroom decorum, attending to students' social and emotional wellbeing, and meeting the conflicting expectations of parents, students, administrators and community. Important factors are : work stressors, such as disruptive students and red tape,, lack of supervisor support,lack of social integration, and the prevalence of job-related self-doubt. Red tape and disruptive students were the strongest predictors.

There are two types of variables that effect burnout ; personality and organizational.From the organizational category there are : role conflict, role ambiguity, work overload, classroom climate and social support. Role conflict involves the quantity of work that teachers are excpected to get done and the quality of work that could be achieved in that time .Also when teachers try to meet the demands of each individual student, in a class of different ability levels. Teachers face discipline problems, where support is limited from parents and principals. Another problem is that curriculum is constantly changing, teaching methodologies are changing to. Teachers are unsure of their roles and they experience emotional exchaustion and reduced sense of personal accomplishment. Work overload is evident through excessive paper work, and oversized classes .Colangelo.T.M(2004; pg.6,7)

Al-Amri (2006, pg.40 ) recommended at the organizational level, adopting a supportive, encouraging, and participative managerial style; organizational goals, expectations, roles, and assignments should be stated clearly; effective communication; good collegial and social support should be encouraged; and professional development (including stress alleviation workshops and workshops on coping with discipline problems). 
Another factor influencing teacher burnout are background variables. Aftab \& Khatoon(2012) based on background studies suggest that gender may be an important demographic characteristic to be considered in the experience of stress .There is a significant difference between male and female teachers, with male teachers having more psychological stress and physical stress than the female teachers. Also, male teachers were reported to be more insecure and emphasized financial concerns, while females expressed concerns about intrinsic facets of their jobs .Moreover, males were observed to have higher stress and anxiety than the females .

Quite contrary to this, female teachers tended to complain more of burnout than male teachers.

Some researchers also fail to advocate any significant result to support a gender difference in their studies regarding level of stress and gender.

\section{Personal and Professional Stressors that Influence Teacher Burnout}

Gold \& Roth (2005, pg.19) group personal stressors into five major areas: health,relationship, financial, recreational , and living conditions. In the beginning teachers is common that by the end of the third week of teaching if no stress reduction program has been introduced they have health problems like colds. On the other hand having to exist on low salary scales determines the type of living conditions and environments in which to raise a family for young teachers.

Across different school settings, researchers have identified a diversity of common stressors that include, among others, students' misbehaviors and discipline problems, poor motivation for work, heavy workload and time pressure, role conflict and role ambiguity, conflicting staff relationships in school administration and management, and pressure and criticisms from parents and the wider community .In confronting these common stressors, teachers however could react very differently. Some might develop mild frustration, anxiety, and irritability to emotional exhaustion. Others might develop more severe psychosomatic and depressive symptoms that require therapeutic interventions .(Chan,2010)

\section{Conclusion}

As (Chan ,2010) states despite all the studies on teacher burnout the clearest conceptualization of burnout is the Maslach and Jackson perspective. They developed a multidimensional standardized measure for research, the Maslach Burnout Inventory (MBI). This framework defines burnout as having three distinct components: emotional exhaustion, depersonalization, and reduced personal accomplishment. Emotional exhaustion refers to the feelings of being emotionally drained by the intense contact with other people; depersonalization refers to the negative attitude or callous responses toward people; and reduced personal accomplishment refers to a decline in one's sense of competence and of successful achievement.

In conclusion components of burnout seem to characterize a life that is in stark contrast to a full or satisfying life.

\section{References}

Aftab.M,Khatoon.T(2012)Demographic differences and occupational stress of secondary school teacher. European Scientific Journal ,vol.8,No.5, pp.159-175

Al-Amri.M.M(2006,pg.41) The impact of In-service Training on Burnout at the Institute of Public Administration.Doctoral Project. uww.fedora.library.cofc.edu

Alarcon .G, Bowling.N.A ,Eschelman .K.J (2009) Relationship between personality variables and burnout: A meta-analysis. Work and stress, Vol.23,No.3,Dayton ,OH,USA

Bitsadze.M\& Japaridze.M(2011) Pilot study of teacher burnout in Georgian context. Problems of management in the 21 th century.Vol.2,No.36

Burke.R.J,Greenglass.E.R, Schwarzer.R(1996)Predicting teacher burnout over time:Effects of work stress,social support and self-doubts on burnout and its consequences.Anxiety, stress, and coping : An International Journal ,vol.9,No.3,Toronto

Byrne ,B.M(1999)Understanding and preventing teacher burnout :A sourcebook of international research and practice,(pp.15-37)New York,N.Y,U.S: Cambridge University Press,XV,362 pp

Chan.D.W(2010) Teacher Burnout Revisited: Introducing Positive Intervention Approaches Based on Gratitude and Forgiveness. Educational Research Journal , vol.25,No.2 Hong Kong

Colangelo.T.M(2004,pg.10)Teacher stress and burnout and the role of Physical Activity and Parent Involvement,Central Connecticut State University.

Dorman.J(2003)Testing a Model for Teacher Burnout .Australian Journal of Education\&Development Psychology.Vol3,2003,pp 35-47 http://psicopolis.com/burnout/budoc1.htm

Evers W.J.G,Brouwers.A,Tomic.W (2002) Burnout and self-efficacy: A study on teachers beliefs when implementing an innovative educational system in the Netherlands. British journal of Educational Psychology.72,227-243 (www.bps.org.uk) 
Gold.Y\&Roth R.A (2005) Teachers managing stress and preventing burnout .Bristol:Taylor\&Francis e-Library,London ,2nd.ed (www.eBookstore.tandf.co.uk)

Johnson.Sh,Cooper.G,Cartwright.S,Donald.I,Taylor.P,Millet.C, (2005). The experience of work -related stress across occupations. Journal of Managerial Psychology .vol.20.No.2,pp.178-187, www.emeraldinsight.com

Panagopoulos.N,Anastasiou.S,Goloni.V (2014)Professional Burnout and Job Satisfaction among Physical Education Teachers in Greece.Journal of Scientific research \&Reports.3(13):1710-1721, www.sciencedomain.org

Terry.P.M (1997) Teacher burnout:Is It real? Can we prevent it? Annual meeting of the north central association of Colleges and Schools.Chicago.IL.Research 143. www.files.eric.ed.gov 